\title{
Two cases of jugular vein thrombosis in severely burned patients
}

\author{
This article was published in the following Dove Press journal: \\ Therapeutics and Clinical Risk Management \\ 12 July 2013 \\ Number of times this article has been viewed
}

\author{
Hanghui Cen \\ Xiaojie $\mathrm{He}$ \\ Department of Burn, The Second \\ Affiliated Hospital, Zhejiang University \\ Medical College, Hangzhou, People's \\ Republic of China
}

\begin{abstract}
Here we present two cases of jugular vein thrombosis in burn patients, with diagnosis, risk factor analysis, and treatment approaches. Severely burned patients have high risk of deep vein thrombosis occurrence due to multiple surgeries. The deep vein catheter should be carefully performed. Once deep vein thrombosis is detected, a wide ultrasonography helps to find other thrombosis sites. During the acute phase, low molecular weight heparin can be used. Upon long-term anti-thrombosis treatment, combined use of herbal medicine during rehabilitation is helpful.
\end{abstract}

Keywords: burn, heparin, combined treatment

\section{Introduction}

Management of burn patients has progressed significantly in recent decades, such as liquid resuscitation, nutrition support, infection control, and multiple woundtreatment strategies. Thrombolytic and fibrinolytic mechanisms are both activated. The endothelial cell damage, blood flow stasis/turbulence, and hypercoagulation are considered as Virchow's triad. ${ }^{1,2}$ In severely burned patients, especially deeply burned patients with sepsis, endothelial cell damage is exacerbated. This changes the coagulation spectrum of the blood. In addition, the lack of movement of burned lower limbs causes the accumulation of venous blood, ${ }^{3}$ hence the high risk of deep vein thrombosis (DVT). ${ }^{4,5}$

It has been reported that burn patients show incidences of DVT from $0.4 \%$ to $7 \%,{ }^{6}$ mainly for the lower limbs. The incidence of upper limb vein thrombosis is low (1\%-4\% among these cases) ${ }^{7}$ which is even rare for jugular vein thrombosis.

Here, we present two cases of jugular vein thrombosis in burn patients, with diagnosis, risk factor analysis, and treatment approaches.

\section{Clinical data and case report}

The two cases described in this report had no previous medical history of abnormal thrombosis.

\section{Case one}

The first patient is male, 53 years old, and was burned by high-temperature alkaline liquid (95\%, second to third degree). The patient was treated with liquid resuscitation, infection control, nutrition support, and 15 surgeries; he has suffered from sepsis, acute renal failure, alimentary tract bleeding, and acute
Department of Burn, The Second Affiliated Hospital, Zhejiang University Medical College, Hangzhou, People's Republic of China

Email hz_hxj@I63.com 
respiration failure. On the 168 th day post-burn $(10 \%$ wound remaining), the patient showed swelling in the left upper limb and axillary space. Ultrasound B examination revealed left axillary venous thrombosis formation. The patient was treated with low-molecular weight heparin calcium $0.4 \mathrm{~mL} /$ day, subcutaneously, and low-molecular dextran needle $500 \mathrm{~mL} /$ day via venous infusion. After 34 days (202 days post-burn), the ultrasound reexamination reported the formation of left jugular and subclavian thrombosis. Warfarin at $3 \mathrm{mg} /$ day was included into the treatment for another week before the dextran needle and heparin calcium treatments were stopped. Then, the dosage of warfarin was adjusted according to the international normalized ratio value (2.0-3.0) for another 47 days, when the ultrasound examination showed recanalization of left axillary vein, while the left jugular thrombosis persisted. The surgery department suggested it was not appropriate for surgical removal or catheter insertion, and the warfarin treatment was continued. At 230 days post-burn, the patient left the hospital, with continued warfarin treatment for 3 months before utilizing traditional Chinese medicine for rehabilitation. Traditional Chinese medicine mainly contains Panax notoginseng (Burk) FH Chen, with bioactive components such as total saponins from the $P$. notoginseng, including $\mathrm{Rg} 1, \mathrm{Rb} 1$, and $\mathrm{R} 1$. The dose was $100 \mathrm{mg}$ three times daily. The treatment followed the guidelines for use of traditional Chinese medicine WS3-B-3207-98.

The ultrasound examination after treatment revealed that left jugular thrombosis disappeared. The final 1-year follow up showed no reoccurrence of thrombosis.

\section{Case two}

The second patient is male, 52 years old, and was burned by boiling water ( $75 \%$, second to third degree). The patient was treated with liquid resuscitation, infection control, nutrition support, and wound recovery. Twenty-eight days later, the patient received skin implantation $(70 \%$ wound healed), with right jugular vein catheter insertion by anesthesiologist. The second day after surgery, the patient showed swelling and pain of the right upper extremity. Ultrasound B examination revealed right proximal jugular vein thrombosis formation, with no changes in the right axillary vein. Subcutaneous low-molecular weight heparin calcium was given $0.4 \mathrm{~mL} /$ day for 7 days, when the swelling disappeared. Then the patient was treated with traditional Chinese medicine products for thrombosis removal as described above. In the follow up at 3 months and 1 year, there was no thrombosis detected.

\section{Results}

Both cases had jugular vein catheter insertion before thrombosis formation and after the major wound healed. The patients reported unilateral upper extremity swelling and pain. The ultrasound examination of the deep vein is necessary and required. The first case showed extension of thrombosis formation, suggesting that the examination should cover a larger area.

Once the thrombosis was diagnosed, low-molecular weight heparin calcium was used. During the same period, the surgery department and hematology department were invited to explore the best treatment approach. In both cases the anticoagulation caused no bleeding, nor other serious complications. Last but not least, the patients took traditional Chinese medicine for antithrombosis during the rehabilitation period. Although the complementary therapy requires a certain amount of experience in treating patients, it can lead to improvement of treatments and the life quality of patients.

\section{Discussion}

DVT of the upper limb is rare. In recent years, incidences have increased, mainly due to cardiac pacemaker implantations and central venous catheters for drug delivery. Yet the reports for jugular vein thrombosis are rare, and the exact formation period is unclear. Upper limb DVT can be divided into primary (including idiopathic effort-related or Paget-Schroetter syndrome and thoracic outlet syndrome) and secondary (provoked by central venous catheters or pacemakers). The latter cases contribute to major cases of upper limb DVT. ${ }^{7-9}$ In present study, both cases occurred in the late phase of treatment, possibly due to the interruption of hemodynamics after multiple surgeries, lack of movement of the lower limb, and mechanical ventilation. We believe that deep vein catheter implantation is the direct cause of DVT in burn patients with hypercoagulable status blood. The proper catheter insertion (eg, under the guidance of ultrasound) might prevent multiple damage to the blood vessels.

With one limb swelling and pain reported, ultrasonography is the easiest and most convenient way to detect DVT formation, compared with Duplex scanning. ${ }^{10,11}$ Additionally, contrast venography is the best way to diagnose DVT, but is difficult in severely burned patients. ${ }^{12}$ Pulmonary angiography by spiral computer tomography or transthoracic Doppler echocardiography can be combined to detect pulmonary embolism if suspected. ${ }^{13}$

The prevention of DVT can be heparin or low-molecular weight heparin. ${ }^{14}$ It has been shown that in burned patients 
with heparin preventing treatment, the incidence of DVT was $0.25 \%-0.3 \%{ }^{3}, 15$ while without such treatment the incidence was $0.9 \%-3 \%{ }^{16,17}$ The treatment to upper limb DVT can refer to the lower limb DVT. ${ }^{9}$ On the other hand, heparin administration can lead to bleeding and reduced platelets; while the use of low-molecular weight heparin has no such complications.

\section{Limitation}

The present study is restricted by the number of cases being only two. We therefore did not perform other control treatment or prospective studies.

\section{Conclusion}

Severely burned patients have high risk of DVT occurrence due to multiple surgeries. Deep vein catheter insertion should be carefully performed. Once DVT was detected, wide-range ultrasonography helps to find other thrombosis sites. During the acute phase, low-molecular weight heparin can be used. Upon long-term antithrombosis treatment, combined use of herbal medicine during rehabilitation may be helpful.

\section{Acknowledgments}

The authors thank the hospital and the university for their support.

\section{Disclosure}

The authors report no conflicts of interest in this work.

\section{References}

1. Wu KK, Thiagarajan P. Role of endothelium in thrombosis and hemostasis. Annu Rev Med. 1996;47:315-331.
2. Abraham WT, Schrier RW. Body fluid volume regulation in health and disease. Adv Intern Med. 1994;39:23-47.

3. Barret JP, Dziewulski PG. Complications of the hypercoagulable status in burn injury. Burns. 2006;32(8):1005-1008.

4. Schulman S. Advances in the management of venous thromboembolism. Best Pract Res Clin Haematol. 2012;25(3):361-377.

5. Ageno W. Recent advances in the management of venous thromboembolism. Korean J Hematol. 2010;45(1):8-13.

6. Fecher AM, O'Mara MS, Goldfarb IW, et al. Analysis of deep vein thrombosis in burn patients. Burns. 2004;30(6):591-593.

7. Elman EE, Kahn SR. The post-thrombotic syndrome after upper extremity deep venous thrombosis in adults: a systematic review. Thromb Res. 2006;117(6):609-614.

8. Kahn SR, Elman EA, Bornais C, Blostein M, Wells PS. Postthrombotic syndrome, functional disability and quality of life after upper extremity deep venous thrombosis in adults. Thromb Haemost. 2005;93(3):499-502.

9. Mai C, Hunt D. Upper-extremity deep venous thrombosis: a review. Am J Med. 2011;124(5):402-407.

10. Desjardins B, Rybicki FJ, Kim HS, et al. ACR Appropriateness Criteria(R) Suspected upper extremity deep vein thrombosis. J Am Coll Radiol. 2012;9(9):613-619.

11. Wester JP, Holtkamp M, Linnebank ER, et al. Non-invasive detection of deep venous thrombosis: ultrasonography versus duplex scanning. Eur J Vascular Surg. 1994;8(3):357-361.

12. Plate G, Akesson H, Einarsson E, Ohlin P, Eklof B. Long-term results of venous thrombectomy combined with a temporary arterio-venous fistula. Eur J Vascular Surg. 1990;4(5):483-489.

13. Frazee BW, Snoey ER. Diagnostic role of ED ultrasound in deep venous thrombosis and pulmonary embolism. Am J Emerg Med. 1999;17(3): 271-278.

14. Abedi N, Papp A. A survey of current practice patterns in prophylaxis against venous thromboembolism (VTE) and gastrointestinal (GI) ulceration among Canadian burn centers. Burns. 2011;37(7): 1182-1186.

15. Ansell JE, Weitz JI, Comerota AJ. Advances in therapy and the management of antithrombotic drugs for venous thromboembolism. Hematology Am Soc Hematol Educ Program. 2000:266-284.

16. Rue LW 3rd, Cioffi WG Jr, Rush R, McManus WF, Pruitt BA Jr. Thromboembolic complications in thermally injured patients. World $J$ Surg. 1992;16(6):1151-1154; discussion 1155.

17. Harrington DT, Mozingo DW, Cancio L, Bird P, Jordan B, Goodwin CW. Thermally injured patients are at significant risk for thromboembolic complications. J Trauma. 2001;50(3):495-499.
Therapeutics and Clinical Risk Management

\section{Publish your work in this journal}

Therapeutics and Clinical Risk Management is an international, peerreviewed journal of clinical therapeutics and risk management, focusing on concise rapid reporting of clinical studies in all therapeutic areas, outcomes, safety, and programs for the effective, safe, and sustained use of medicines. This journal is indexed on PubMed Central, CAS,

\section{Dovepress}

EMBase, Scopus and the Elsevier Bibliographic databases. The manuscript management system is completely online and includes a very quick and fair peer-review system, which is all easy to use. Visit http://www.dovepress.com/testimonials.php to read real quotes from published authors. 